American Journal of Applied Sciences 7 (6): 784-789, 2010

ISSN 1546-9239

(C) 2010Science Publications

\title{
Study on the Thermal Accumulation and Distribution Inside a Parked Car Cabin
}

\author{
Hussain H. Al-Kayiem, M. Firdaus Bin M. Sidik and Yuganthira R.A.L Munusammy \\ Department of Mechanical Engineering, University Technology PETRONAS, \\ Bandar Seri Iskandar, 31750 Tronoh, Perak, Malaysia
}

\begin{abstract}
Problem statement: When a vehicle is parked under the direct sun, the accumulated heat is affecting many interiors inside the vehicle cabin, such as the vinyl materials of the dashboard, the leather covers and the electronic components. Also, it represents an uncomfortable operating period for the passengers. The studies under this topic are entitled by the vehicle manufacturers as "Vehicle Cabin Comfort". Approach: In the present study, experimental and numerical analyses were conducted. The experimental results were obtained from measurements on a salon car parked in unshaded area. Six different cases had been investigated consisting of full windows closing case, four different windows opening settings and sun shade usage case. The temperature at 12 different locations inside the car had been recorded for many days and the mean values are used as initial and boundary conditions to run the 3-D computational simulation. The CFD simulation was carried out by FLUENT software. Results: Both experimental and CFD simulation results revealed that the most hot air was accumulated in the top part of the cabin and natural circulation take place with large scale cavity due to natural heat transfer from the dashboard and the rear windshield. The drop down of the front side windows by $20 \mathrm{~mm}$ caused reduction in the front air gap by $20 \%$. The sunshade on the front had considerably reduced the heat accumulation inside the cabin, where the dashboard surface temperature dropped by $26 \%$ and the maximum air temperature was found to be $27 \%$ lower. Conclusion: The use of the sunshade and/or dropdown windows on both sides reduced the heat accumulation due to fresh air exchange with the exterior environment.
\end{abstract}

Key words: Vehicle cabin comfort, CFD simulation, thermal analysis, cars ventilation

\section{INTRODUCTION}

The problem that is faced by many car users today is a hot interior after certain hours of parking in open air or un-shaded parking area. The heat under such parking condition causes the car cabin and interior temperature to increase up to $80^{\circ} \mathrm{C}$ average. The accumulation of thermal energy inside the vehicle with undesired temperature rise would cause the interior parts to degrade because they normally are subjected to wear and tear. Degradation may shorten the life span of the various components inside the car. Passengers are also being affected with the thermal condition inside the vehicle itself. The car user is forced to wait for a period of time around 2-5 min before getting into the car to cool down the interior condition either by rolling down the window or running the air conditioner at high speed that really affect the fuel consumption.

In developing the automotive heating/ventilating/air conditioning, HVAC systems, Computer Aided
Engineering could be used to enhance the design efficiency. Based on ASHRAE 2-node human skin model, Taniguchi (2001) of Kansei-Psychology Labs has developed a computational simulation to predict the occupant's temperature sensation and thermal comfort by non-steady, non uniform thermal environment in the car cabin.

Han et al. (2001) has developed a vehicle thermal comfort model to evaluate the performance of many (HVAC) system designs that was ever possible in the past. The model used CFD technique to predict the local thermal comfort as a function of air temperature, surface temperature, humidity, direct solar flux, as well as the level of activity and clothing type of each individual.

Martinho et al. (2004) studied the thermal comfort in a car cabin through measurements of the flow velocity and temperature at different operating conditions using equivalent temperature index. Results were obtained from measurements on a life-size laboratory model with and without thermal mannequin

Corresponding Author: Hussain H. Al-Kayiem, Department Mechanical and Engineering, University Technology PETRONAS, 31750 Tronoh, Perak, Malaysia 
by scanning the velocity and temperature at various planes inside the cabin.

Akiko et al. (2007) of Honda R\&D have studied the effect of cabin environment on the driver fatigue. The subjective experiments were carried out on a chamber in order to develop the driver's fatigue model. Hodder and Parsons (2007) have investigated the relation between simulated solar radiation and thermal comfort. In this work, three effects were studied, (1) the intensity of direct simulated solar radiation, (2) spectral content of simulated solar radiation and (3) glazing type on human thermal sensation responses. They concluded that increase in total intensity of simulated solar radiation rather than the specific wavelength of the radiation is the critical factor affecting thermal comfort.

Some solutions are suggested in this topic. Toyota HVAC designers have suggested the installation of Solar Powered Ventilation System which uses an electric fan to draw outside air into, through AND out of the cabin once the inside temperature reaches $68^{\circ}$ Fahrenheit. This will lower the cabin temperature to near the outside ambient temperature to help make the cabin more comfortable when re-entering the vehicle. It must be turned on prior to leaving the vehicle and cannot perform cooling such as with an air conditioner.

The "Car Cabin Climate Control" is the result of the "Thermal Comfort Engineering". Many automotive manufactures sooner or later will adopt techniques which now days can be seen only on the luxury cars due to the considerable cost involved. This concern on the comfort level of the occupants in the car, due to the internal climate, needs additional systems implementation to provide desirable level of comfort.

The present study aims to provide further information on the nature of the thermal behavior as the solar heat transfer to the car cabin. The objective of this study is to present results from experimental measurements and computational simulation to investigate the temperature distribution on the surfaces and the air cavity in the car cabin. The CFD simulation was conducted using FLUENT software. The basic CFD model of the car was quoted from ASHRAE standard and the boundary and initial conditions are adopted from the experimental environment.

\section{MATERIALS AND METHODS}

Experimental procedure: The vehicle selected for the experimental measurement was located in the same place and same orientation during the entire experimental measurement program, as in Fig. 1.

Experimental methodology: Six different parking conditions were investigated consisting of different side glass windows openings, front shield shading and normal parking condition. The cases are described in Table 1.

The measurements were taken 3 times for three days to reduce the uncertainty. For each day, the measurements started at 9.00 am till 4.00 am and the data was recorded on $1 \mathrm{~h}$ step interval.

Experimental measurements: The main parameter in the experimental measurements is the temperature. The ambient temperatures at 12 different spots inside the car cabin were selected as shown in Table 2 . Three locations were selected for the air temperature records and nine locations for the surfaces temperature distribution in the cabin.

The temperatures were measured by thermocouple wires type $\mathbf{J}$ in conjunction with 20 channel data logger. Only 13 channels were used for the cabin interior surfaces, cabin air and ambient temperatures.

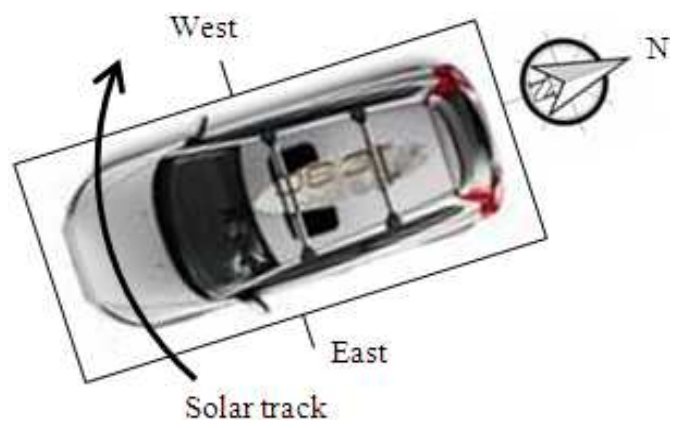

Fig. 1: The vehicle orientation during the measurements

Table 1: Description of the experimental measurement cases

\begin{tabular}{ll}
\hline Test case & Description \\
\hline 1 & All windows are closed \\
2 & Both windows at back were rolled down for $1 \mathrm{~cm}$ \\
3 & Both windows at back were rolled down for $2 \mathrm{~cm}$ \\
4 & Sunshade is placed under the front windshield \\
5 & Both windows at front back were rolled down for $1 \mathrm{~cm}$ \\
6 & Both windows at front back were rolled down for $2 \mathrm{~cm}$ \\
\hline
\end{tabular}

Table 2: Temperature measurement spots inside the car

\begin{tabular}{ll}
\hline Location of the Measuring Points (MP) & Type \\
\hline Dashboard & Surface \\
Space for leg -near firewall (passenger side) & Air \\
Under roof & Surface \\
On left passenger seat & Surface \\
Front windshield & Surface \\
Back windshield & Surface \\
On back seat & Surface \\
Front side (hanging in between driver and passenger seat) & Air \\
Head support of seat (front passenger) & Surface \\
Side window (left back passenger) & Surface \\
Back side (hanging at the centre) & Air \\
Side window (driver side) & Surface \\
\hline
\end{tabular}


The solar radiation was measured by digital Solarimeter at four different locations (the front and back windshields and the glass of the sides' windows). The data was recorded inside and outside the cabin near the glass.

Numerical procedure: The thermal accumulation in the car cabin was modeled, simulated and analyzed. All the experimental cases were verified using CFD simulation. The results obtained from the two procedures were compared and discussed.

Car cabin modeling: The 3-D model prepared using GAMBIT software, is shown in Fig. 2. In this model the driver and passenger bucket seats are excluded to simplify initial simulation process. This model outlines were selected according to ASHRAE Standards for car cabin modeling (ASHRAE Handbook Fundamentals, 1993). The geometries were quoted from the actual car which was subjected to experimental measurements. The total volume of the fluid in the cabin is $2.289 \mathrm{~m}^{3}$ and the total fenestration area is $3.0201 \mathrm{~m}^{2}$. The front wind shield area is $0.8072 \mathrm{~m}^{2}$, the rear wind shield area is $0.6841 \mathrm{~m}^{2}$ and the side glass windows area is $0.7644 \mathrm{~m}^{2}$. The ASHRAE basic model of the car cabin was developed by including the opening of the side windows. In Fig. 3, the rear side windows are opened with $20 \mathrm{~mm}$ gap.

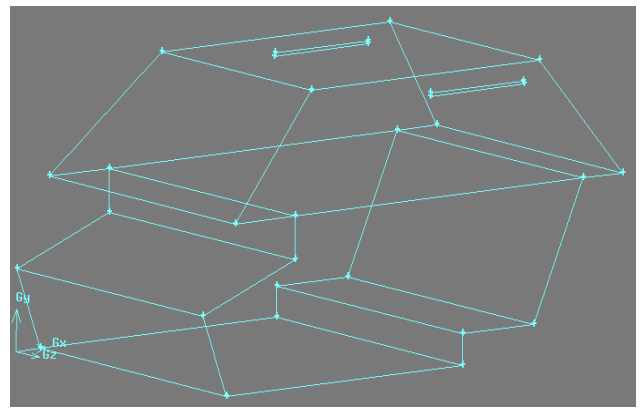

Fig. 2: 3-D Cabin Model based on ASHRAE standard

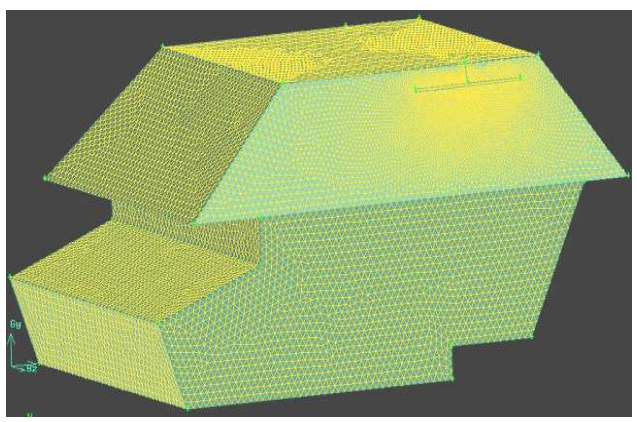

Fig. 3: 3-D Finite volume structured grid of the model
Meshing criteria: The discretization of the fluid domain inside the cabin to finite volumes was achieved by using GAMBIT software. Only tetrahedral finite volume type was successfully applied to the model. Compared to the quadrilateral, the tetrahedral produces more accurate results. This is due to the non uniform geometrical shape of the model under investigation. Interval size of 15 unit and structured grid near the glass surfaces and the windows opening was used. The 3-D finite volume discretized model is shown in Fig. 3.

Simulation: The model prepared in GAMBIT was exported to FLUENT version 6.2. P-1 radiation model is used to simulate the thermal process of the car cabin, where both radiation and convection heat transfer were included in the simulation.

The boundary and initial conditions to run the simulation were based on the experimental data. The Initial condition of air cabin temperature and surface temperatures were set at $300 \mathrm{~K}$.

\section{RESULTS}

The results of the six cases presented earlier in Table 1were plotted to show the transient behavior of the solar radiation during the experiments.

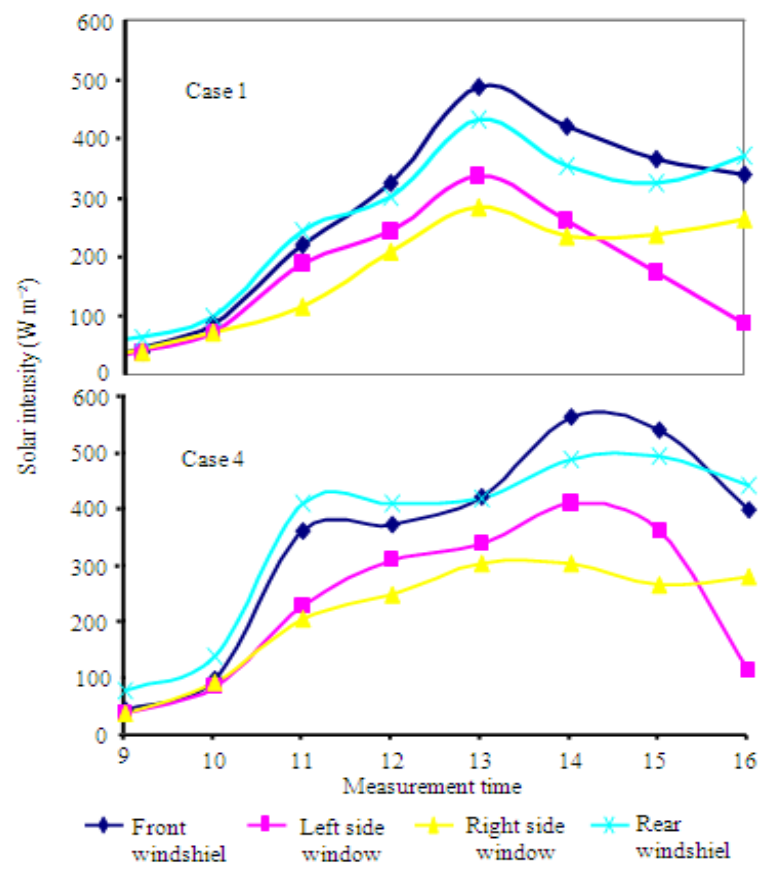

Fig. 4: The solar intensity results on the four sides of the cabin during measurements of Case 1 and Case 4 
The 3 days mean values of the measured irradiation during case 1 and case 4 experiments are shown as a sample in Fig. 4.

The results of the temperature measurements inside the cabin are presented in Fig. 5 and 6 for case 1 and case 4, respectively. In Fig. 5 and 6, there are 12 measurement locations. The transient variation of the temperature was covered for measurement period from 9.00 am to $4.00 \mathrm{pm}$.

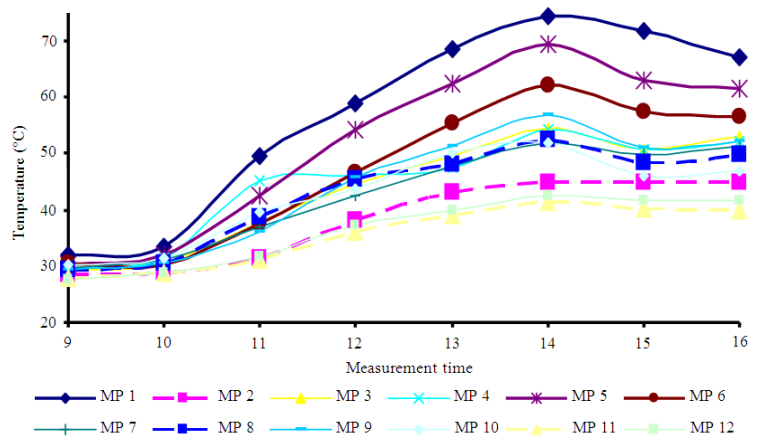

Fig. 5: Measured temperatures in the car cabin, Case 1: All windows are closed

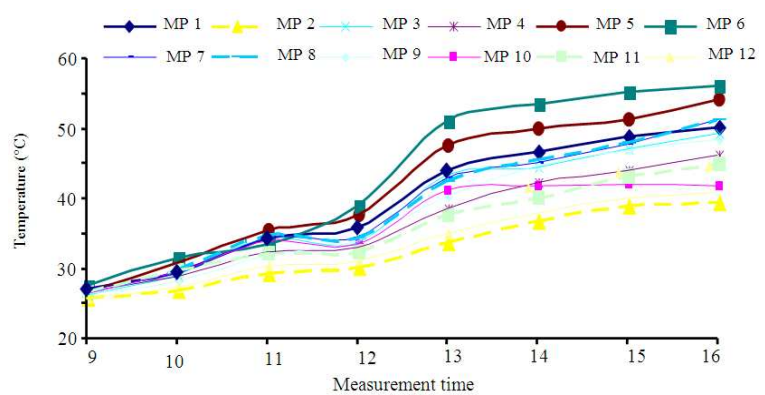

Fig. 6: Measured temperatures in the car cabin, Case 4: All windows are closed but sunshade underneath the front windshield

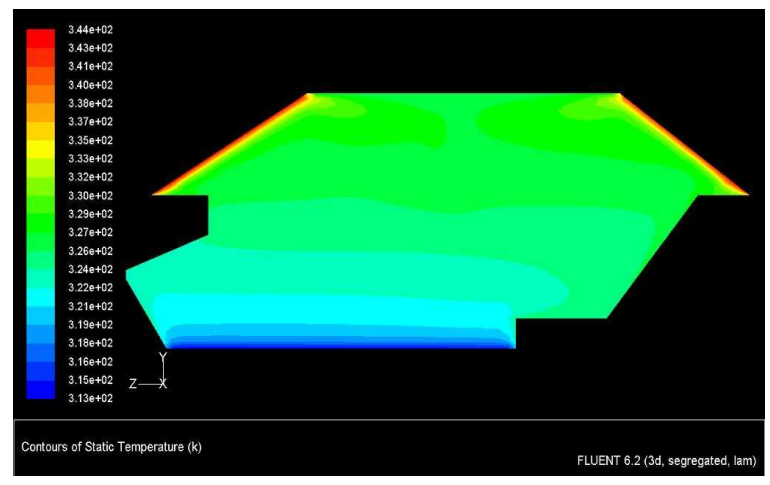

Fig. 7: Numerical simulation results of the temperature distribution in the cabin, all windows are closed
The numerical simulation results are presented as temperature distribution and air motion inside the cabin. Fig. 7 shows the temperature distribution inside the cabin when all windows are closed, at $12.00 \mathrm{am}$.

\section{DISCUSSION}

The irradiation varied during the measurement duration from 9.00-4.00 pm. The solar irradiation was measured at four different spots on the glass of the car. The peak irradiation was recorded between 12:00-2:00 pm with approximate mean value of $500 \pm 50 \mathrm{~W} \mathrm{~m}^{-2}$ depending on the cloud conditions.

All of the surface measurements results inside the car have shown that the highest temperatures are recorded in the spots near the glass windshields. Meaning that the spots exposed directly to transmitted solar radiation has accumulated thermal energy more than the interior spots subjected to convective heat transfer.

In the results shown in Fig. 5 and 6, those spots are indicated by point 1 on the dashboard and point 6 on the back surface near the rear windshield. Air temperature measurements revealed that the highest air temperature was near the roof. This is noticed from the simulation as well.

In measurements of case1, where all windows are closed, the dashboard temperature, DBT was raised up to $75^{\circ} \mathrm{C}$. (Martinho et al., 2004) recorded $80^{\circ} \mathrm{C}$ on the dashboard. The DBT exceeded the $70^{\circ} \mathrm{C}$ for the period between 12.30 and $2.30 \mathrm{pm}$. The opening of the rear windows, cases 2 and 3, did not shown noticeable effect on the DBT. The air temperature at the back reduced slightly due to the $20 \mathrm{~mm}$ opening of the rear windows.

Using sunshade (Case 4) underneath the front windshield, (Case 4), reduced the temperature on the dash board surface considerably. The maximum DBT in case 1 is $75^{\circ} \mathrm{C}$, as in Fig. 3, while in case 4 it reduced to $50^{\circ} \mathrm{C}$ as in Fig. 4. Consequently, all the measured temperatures have shown lower values compared with Case 1.

Measurement results of case 6 , where the front windows were dropped down by $20 \mathrm{~mm}$ showed effective reduction in the front air temperature measuring point. Its maximum value in the case of full close reached $52^{\circ} \mathrm{C}$, while in this case it reached $42^{\circ} \mathrm{C}$. The openings have caused circulation between the warm air inside the cabin and the ambient air.

From the numerical simulation, it was noticed that the highest temperature spots are close to the front and rear glass windshields, (Fig. 7). The warmest air regions are near the top roof and near the windshield glass at the front and the rear. The velocity simulations presented in 
contour map, as in Fig. 8 have shown that there are two circulation cavities in the upper half of the cabin.

There is a continuous thermal energy supply to the air from four sources; all of them are by convection. The highest heat source is the dashboard surface and there is heat transfer from the front and rear glass windshields and finally from the roof surface. The circulation occurs due to the relatively large amount of heat transfer from the dashboard, which then, producing buoyancy effect.

The simulation results with sun shed installation near the front glass wind shield showed that the temperature of the dashboard has reduced considerably. This is also experienced in the experimental measurement and hence the CFD simulation is validated. The 3-D animation simulation of the air motion shown in Fig. 9 clearly indicates the circulation of air particles from the front windshield to the upper portion of the cabin. The natural convection from the rear and front windshields maintain the circulation and the raising up of the temperature in the upper portion of the cabin.

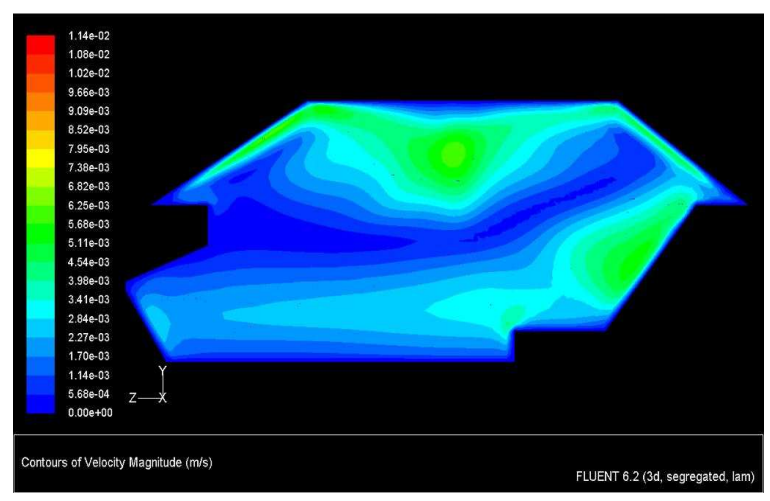

Fig. 8: Numerical simulation of the velocity contours

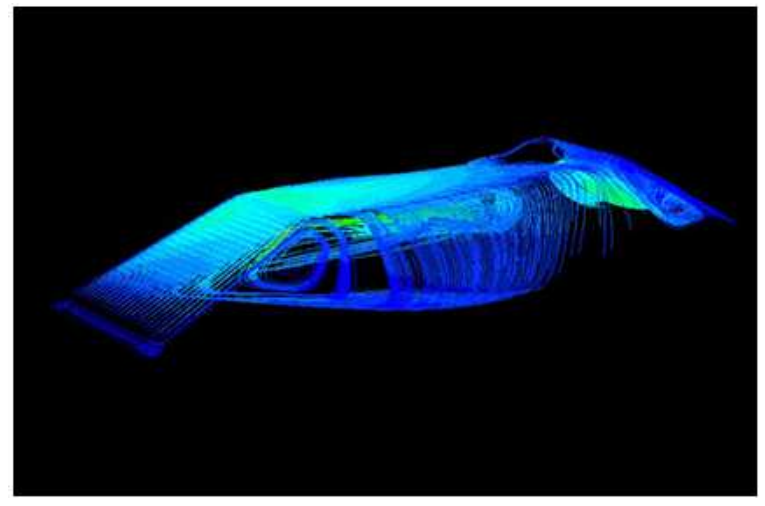

Fig. 9: Animation simulation results of velocity contours
The animation has shown that there are two circulation cavities in the upper half of the cabin. There is a continuous thermal energy supply to the air from four sources; all of them are by convection. The highest heat source is the dashboard surface and there is heat transfer from the front and rear glass windshields and finally from the roof surface. The circulation occurs due to the relatively large amount of heat transfer from the dashboard, which then, producing buoyancy effect.

\section{CONCLUSION}

Study on the 'car cabin comfort' had been carried out experimentally and numerically. The experimental results have been obtained by a measurements program conducted on a car prototype. The measurements were carried out during the sunny time under non shaded parking environment. Three-dimensional CFD simulation using FLUENT 6.2 code was carried out under 3-D radiation heat transfer model. Simulation of the temperature distribution inside the car has been verified by comparing with the experimental data. Both experimental and CFD simulation results indicate that the dashboard functioning as a sink of solar radiation and source of convection heat transfer to the adjacent air particles. Large air circulation cavity above the dashboard and small air circulation cavity near the rear upper part with stagnant portion between the two cavities were observed. The sun shade installation underneath the front windshield reduced the thermal accumulation considerably. Generally speaking, it reduced the temperature by about $27 \%$ inside the car cabin. Accordingly, its use is highly recommended. The drop down of the front side windows by $20 \mathrm{~mm}$ caused reduction in the front air gap by $20 \%$.

\section{ACKNOWLEDGMENT}

The researchers acknowledge University Technology PETRONAS for the technical support during the research program and for support for publication.

\section{REFERENCES}

Akiko, A., T. Hitomi, H. Yoshitaka and T. Shini, 2007. Effects of car cabin environment on driver's comfort and fatigue. Proc. JSAE Ann. Cong., 72: 13-16.

ASHRAE Handbook Fundamentals, 1993. HVAC Applications. American Society of Heating, Refrigerating and Air-Conditioning Engineers. http://www.ashrae.com 
Han, T., L. Huang, S. Kelly, C. Huizenga and H. Zhang, 2001. Virtual Thermal Comfort Engineering. SAE Technical Paper Series 2001-01-0588.

Hodder, S.G. and K. Parsons, 2007. The effect of solar radiation on thermal comfort. Int. J Biometeorol., 51: 233-250. DOI: 10.1007/s00484-006

Martinho, N.A.G., M C.G. Silva and J.A.E. Ramos, 2004. Evaluation of thermal comfort in a vehicle cabin. J. Automob. Eng., 218: 159-166. DOI: $10.1243 / 09544070477291393$
Taniguchi, Y., 2001. Simulation model for predicting car occupants; thermal comfort. R\&D Rev. Toyota CRDL, 36: 1-2. http://www.tytlabs.co.jp/english/review/rev362epdf /e362_063taniguchi.pdf 